\title{
Pemaknaan Potensi Lokal di Desa Wisata Rawabogo Kabupaten Bandung
}

\author{
Alma Verdiana* \\ Prodi Perencanaan Wilayah dan Kota, Fakultas Teknik, Universitas Islam \\ Bandung, Indonesia. \\ *alma.verdiana@gmail.com
}

\begin{abstract}
The tourism potential of Rawabogo Village became one of the urgencies after the establishment of the tourism village title in the village. Rawabogo Village, which is located in Ciwidey District, has been designated as a tourism village since 2011 with the potential for the Gunung Nagara Padang Site. However, until now this potential has not shown significant development. Rawabogo Tourism Village needs to explore the meaning of this phenomenon in order to know the real local potential. Based on this phenomenon, the method needed in addition to the instrumental concept (disstantiation) is also required for its meaning (appropriation). This research method uses a symbolic hermeneutic approach (Paul Ricoeur) which offers a new paradigm in the field of tourism village planning. This approach describes the meaning by combining "explanation" and "understanding" of the information unit to produce meaning of local potential through a process of disstantiation and appropriation in accordance with the needs of meaning in the Rawabogo Tourism Village. The results of the analysis resulted in the meaning of the local potential of the Rawabogo Tourism Village, namely culture as the identity of the cultural community and the potential attractiveness of Rawabogo Village, Gunung Nagara Padang as a characteristic of Rawabogo Village, and the diversity of attractions as an opportunity for Rawabogo Tourism Village. The meaning of the local potential can be an option for the direction of the tourism potential of the Rawabogo Tourism Village.
\end{abstract}

Keywords: Tourism Village, Disstantiation, Appropriation, Culture

Abstrak. Potensi wisata Desa Rawabogo menjadi salah satu urgensi setelah ditetapkannya gelar desa wisata pada desa tersebut. Desa Rawabogo yang berlokasi di Kecamatan Ciwidey telah ditetapkan menjadi desa wisata sejak tahun 2011 dengan potensi adanya Situs Gunung Nagara Padang. Namun hingga kini potensi tersebut belum menunjukkan perkembangan signifikan. Desa Wisata Rawabogo perlu menggali pemaknaan fenomena tersebut agar dapat mengetahui potensi lokal sebenarnya. Berdasarkan fenomena tersebut maka metode yang dibutuhkan selain pada konsep instrumentalnya (distansiasi) diperlukan juga pemaknaannya (apropriasi). Metode penelitian ini menggunakan pendekatan hermeneutik simbolis (Paul Ricoeur) yang menjadi penawaran paradigma baru dalam bidang perencanaan desa wisata. Pendekatan tersebut mendeskripsikan pemaknaan dengan menggabungkan antara "penjelasan" dan "pemahaman" atas unit informasi untuk menghasilkan pemaknaan potensi lokal melalui proses distansiasi dan apropriasi yang sesuai dengan kebutuhan pemaknaan di Desa Wisata Rawabogo. Hasil dari analisis menghasilkan pemaknaan potensi lokal Desa Wisata Rawabogo yaitu budaya sebagai identitas masyarakat budaya dan potensi daya tarik Desa Rawabogo, Gunung Nagara Padang sebagai ciri khas Desa Rawabogo, dan keberagaman daya tarik sebagai peluang Desa Wisata Rawabogo. Pemaknaan potensi lokal tersebut dapat menjadi opsi arah potensi wisata dari Desa Wisata Rawabogo.

Kata Kunci: Desa Wisata, Distansiasi, Apropriasi, Budaya 


\section{A. Pendahuluan}

Desa Wisata adalah suatu wilayah pedesaan yang memiliki struktur kehidupan masyarakat dengan tradisinya yang berlaku dan menyatu dengan atraksi, akomodasi dan fasilitas pendukung sebagai unsur pariwisata. Desa Wisata Rawabogo merupakan salah satu desa wisata di Kabupaten Bandung dengan potensi situs megalitikum Gunung Nagara Padang. Desa Rawabogo ditetapkan sebagai desa wisata oleh Bupati Kab. Bandung sejak tahun 2011, namun hingga kini belum terlihat signifikan pengembangan daya tarik desa wisatanya. Selain itu, Desa Rawabogo sempat mengalami kehilangan potensi budaya sehingga perlu bangkit untuk mempersiapkan potensi lokalnya dengan melakukan pemaknaan terhadap desa tersebut.

Pemaknaan dapat dilakukan dengan berbagai cara seperti pendekatan semiotika, fenomenologi, spirit ruang dan hermeneutik. Hermeneutik simbol dari Paul Ricouer merupakan salah satu pendekatan dalam pemaknaan yang memiliki kesesuaian dengan penelitian ini. Menurut Ricouer, hermeneutika adalah teori mengenai hubungan antara pemahaman dengan interpretasi teks dan dapat diterapkan dalam memaknai simbol, teks, dan teks-aksi-sejarah homolog. Pokok gagasan hermeneutik Ricouer menawarkan metode hubungan dialektis antara "memahami" dan "menjelaskan".

Kesesuaian pendekatan hermeneutik Paul Ricouer dalam penelitian ini didasarkan pada munculnya fenomena di Desa Wisata Rawabogo yang memerlukan pemaknaan potensi lokal. Seperti fenomena utama terkait adanya potensi desa wisata sejak 2011 namun hingga kini belum berkembang lebih jauh, dan fenomena/ permasalahan lainnya yang muncul sebagai teka-teki. Berdasarkan fenomena, penyelidikkan Desa Rawabogo tidak cukup dengan menggunakan konsep yang cenderung berkembang saat ini yaitu konsep instrumental seperti konsep 4A Pariwisata ataupun RTIS, lalu konsep komunikatif (seperti CBT) yang merupakan suatu metode menganalisis (distansiasi) atau "penjelasan". Namun, penyelidikkan perlu dilanjutkan dengan pemaknaan mendalam pada fenomena yang terjadi di Desa Rawabogo yang berarti perlu langkah memahami secara kritis (apropriasi) atau suatu "pemahaman".

Penelitian terdahulu mengenai hermeneutik Paul Ricouer belum menyentuh pada ranah Perencanaan Wilayah dan Kota. Sedangkan penelitian terdahulu terkait Desa Rawabogo lebih kepada penyelidikkan potensi tanpa penggalian makna serta penelitian penyelidikkan makna namun khusus pada Situs Gunung Nagara Padang. Maka dari itu, pertanyaan penelitian yang dapat dikemukakan berdasarkan latar belakang yaitu, "Bagaimana pemaknaan potensi lokal melalui hasil distansiasi dan apropriasi di Desa Wisata Rawabogo?". Penelitian ini bertujuan untuk mendeskripsikan pemaknaan potensi lokal dengan langkah distansiasi dan apropriasi sebagai upaya mengetahui pemaknaan dibalik fenomena Desa Wisata Rawabogo.

\section{B. Metodologi Penelitian}

Metode pendekatan penelitian yang digunakan yaitu fenomenologi hermeneutik simbolis (Paul Ricoeur) yang memiliki bentuk data kualitatif dan analisis deskriptif kualitatif. Proses analisisnya melibatkan tahap distansiasi dan appropriasi pada unit informasi untuk kemudian dikolaborasikan dan menghasilkan pemaknaan [6]. Pemaknaan tersebut melalui gabungan antara hasil deskripsi distansiasi (penjelasan dan otonomi unit informasi), dan hasil deskripsi apropriasi (pemahaman kritis setelah dilakukan distansi, pemaknaan unit informasi yang muncul di fenomena Desa Wisata Rawabogo).

Metode pengumpulan data dilakukan dengan observasi sebanyak 5 waktu survey, lalu wawancara dengan purposive sampling dan melalui dokumen/ arsip yang tersedia serta hasil diskusi dengan pemuda desa. Metode analisis data dilakukan dengan tahapan distansiasi (erklaren/ menjelaskan) dan appropriasi (verstehen/ memahami) kemudian dilakukan dialog antar analisis yang menghasilkan pemaknaan. Tahapan analisis dijelaskan pada gambar berikut. 


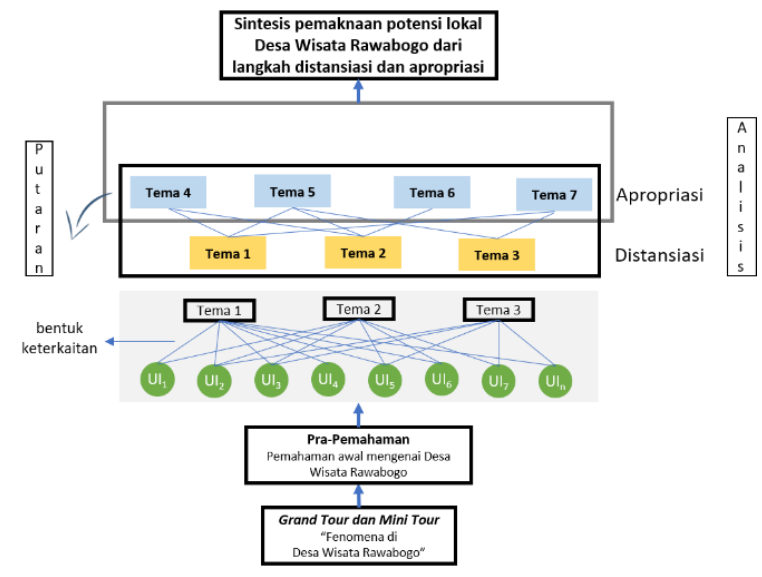

Gambar 1. Tahap Proses Penelitian

\section{Hasil dan Pembahasan}

Berdasarkan hasil tahap grand tour, mini tour dan proses pra-pemahaman maka didapatkan gambaran unit informasi/ teks yang muncul di Desa Wisata Rawabogo dan diklasifikasikan dalam tema penelitian (Gambar 2). Tema penelitian awal yang dihasilkan yaitu, budaya dan kebudayaan, daya tarik, pengelola dan kelompok, kehidupan desa, dan fasilitas. Setelah tema penelitian awal didapatkan maka dilanjutkan dengan tahap analisis distansiasi dan apropriasi yang berarti tahap apropriasi dideskripsikan setelah tahap distansiasi dengan melibatkan hasil analisis distansiasi yang telah dideskripsikan sebelumnya (Gambar 3).
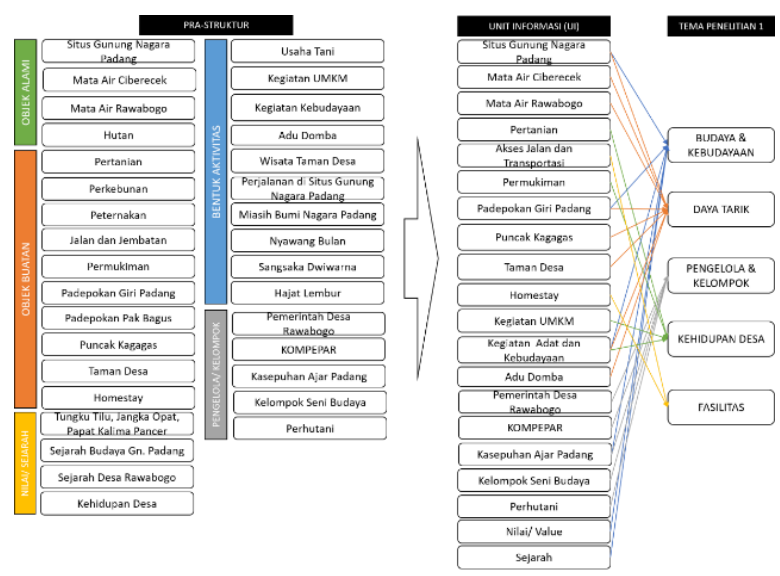

Gambar 2. Identifikasi Unit Informasi

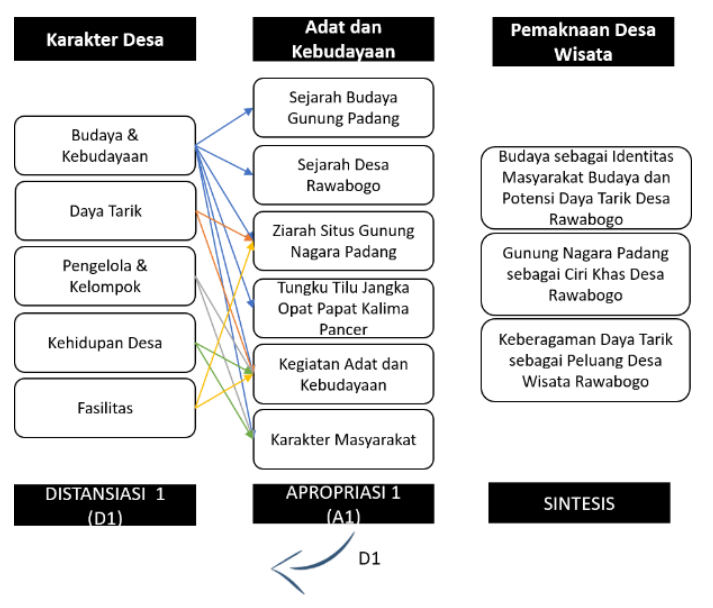

Gambar 3. Tema Penelitian Pemaknaan Desa Wisata Rawabogo 
Berikut hasil analisis pemaknaan potensi lokal Desa Wisata Rawabogo dari tahap distansiasi, apropriasi serta sintesis pemaknaan.

\section{Karakter Desa (Distansiasi)}

1. Budaya dan Kebudayaan

Budaya dan kebudayaan di Desa Rawabogo memiliki ciri khas dan dominan kegiatannya. Budaya dan kebudayaan menjadi salah satu faktor utama daya tarik pengunjung ke Desa Rawabogo. Kegiatan budaya dan kebudayaan tersebut yaitu ziarah Situs Gunung Nagara Padang, Miasih Bumi Nagara Padang, Nyawang Bulan, Sangsaka Dwiwarna, Hajat Lembur, Adu Domba, kegiatan seni budaya dan cerita budaya. Sintesis distansiasi budaya dan kebudayaan yaitu Desa Rawabogo memiliki ciri khas kegiatan budaya dan kebudayaan yang masih melekat pada masyarakat adat. Masyarakat umum desa mengetahui potensi budayanya namun tidak sedalam pengetahuan budaya dari masyarakat adat. Seluruh budaya dan kebudayaan tersebut telah menarik minat pengunjung luar desa dan rutinnya kegiatan dapat berpotensi menjadi daya tarik.

2. Daya Tarik

Daya tarik merupakan suatu hal yang menjadi keunikan dari Desa Rawabogo dan menarik minat pengunjung luar desa. Daya tarik di Desa Rawabogo yaitu Situs Gunung Nagara Padang, Mata Air Ciberecek, Mata Air Rawabogo, Padepokan Giri Padang, Puncak Kagagas dan Taman Desa Rawabogo, serta pertunjukkan adu domba. Sintesis distansiasi pada daya tarik yaitu Desa Rawabogo memiliki daya tarik terkait kegiatan budaya dan kebudayaan serta alamnya. Daya tarik unggul yang sudah cukup berkembang yaitu kegiatan budaya karena adanya Situs Gunung Nagara Padang. Daya tarik tersebut menjadi salah satu faktor utama ketertarikan dari pengunjung luar desa. Namun, daya tarik budaya terkhususkan pada pengunjung yang menggemari budaya kebudayaan saja.

3. Pengelola dan Kelompok

Pengelola dan kelompok-kelompok merupakan salah satu komponen penting dalam berkembangnya suatu desa. Pengelola dan kelompok memiliki fungsi dan tujuan masing-masing namun dapat bersinergi untuk membentuk kesatuan. Pengelola dan kelompok di Desa Rawabogo yaitu Pemerintah Desa Rawabogo, KOMPEPAR, PERHUTANI, Karang Taruna, tokoh agama, Kelompok Kasepuhan Ajar Padang, Komunitas Pamidangan Cipta Mandiri, kelompok-kelompok seni budaya, kelompok tani, Komunitas Pedagang Keliling (KOMPAK), dan kelompok-kelompok UMKM. Sintesis distansiasi pada pengelola dan kelompok yaitu Desa Rawabogo memiliki dominan kelompok-kelompok budaya dan potensi kelompok penggerak wisata. Kelompok-kelompok terlihat berjalan secara mandiri dan tidak ada wadah kolaborasi bersama yang berkelanjutan. Kelompok yang telah mengelola kegiatan dengan cukup baik yaitu Komunitas Kasepuhan Ajar Padang (Padepokan Giri Padang) yang mengelola kegiatan budaya dan Komunitas Pamidangan Cipta Mandiri (eksternal) yang telah mengelola pertunjukan Adu Domba.

4. Kehidupan Desa

Kehidupan Desa Rawabogo secara umum memiliki kegiatan yang sama seperti desadesa pada umumnya. Selain itu kegiatan adat kebudayaan dan kearifan lokal masih dilakukan. Kearifan lokal memberikan nilai dan pandangan yang menyatu dengan alam semesta. Menurut Fitri, kehidupan masyarakat Sunda memiliki sifat kasundaan dalam menuju kehidupan utamanya seperti cageur (sehat), bageur (baik), bener (benar), singer (mawas diri) dan pinter (cerdas, pandai). Dalam kehidupan masyarakat budaya Desa Rawabogo ini memiliki keutamaan melakukan silihwangi, welasasih, rohman rohim, sapajajaran yang merupakan prinsip ruratreret, prinsip silih asah-asih-asuh, prinsip amal ibadah dan keadilan. Sintesis distansiasi kehidupan desa yaitu Desa Rawabogo memiliki kehidupan masyarakat yang bergantung pada kegiatan pertanian (utama) dan adanya tradisi budaya yang masih melekat. Kehidupan desa Sunda tersebut seperti sikap, perilaku yang menjadi kebiasaan orang Sunda, kegiatan khas Sunda yang menjadi warna tersendiri di desa tersebut. Namun, prinsip dan budaya Sunda kini tidak sepenuhnya berjalan di kehidupan masyarakat umum Desa Rawabogo. 
5. Fasilitas

Fasilitas merupakan pemenuhan kebutuhan masyarakat desa dan fasilitas umum sebagai pemenuhan kebutuhan pengunjung luar desa. Fasilitas umum terdiri dari penginapan/ homestay, toilet, musholla, warung, tempat makan, tempat istirahat, akses jalan transportasi, dll. Setiap homestay menyediakan toilet, tempat ibadah/ musholla dan menyediakan menu makan. Sintesis distansiasi pada fasilitas yaitu secara umum di Desa Rawabogo sudah terdapat beberapa homestay, warung kecil, tempat beristirahat, masjid, dan akses jalan utama yang cukup baik. Fasilitas tersebut memiliki kondisi cukup baik namun kurang terhadap kebersihan dan kesiapan akan kehadiran pengunjung luar desa. Apabila dikaitkan dengan daya tarik, maka Padepokan Giri Padang sudah dekat dengan lokasi fasilitas yang lebih baik dibandingkan daya tarik lainnya. Daya tarik dan ketersediaan fasilitas berpengaruh signifikan bagi kepuasan pengunjung.

\section{Adat dan Kebudayaan (Apropriasi)}

1. Sejarah Budaya Gunung Padang

Sejarah dari Gunung Padang terdapat dalam 3 naskah Sunda kuno yaitu Wawacan Sajarah Galuh (abad 19), Carita Pantun Ciung Wanara, Carita Parahyangan (1579) yang berkaitan dengan tokoh Prabu Permana Di Kusumah. Gunung Padang sebagai tempat yang mengangkat sakralitas dengan menjunjung tradisi atau ziarah. Melakukan tradisi sama dengan penghormatan terhadap kabuyutan dan dapat membuka berkah dari Yang Maha Kuasa. Selain itu, Gunung Padang juga sebagai tempat bertapa dan mengasingkan diri, membentuk diri untuk mencapai kesaktian. Pada Situs Gunung Nagara Padang proses penyadaran dan pengembangan diri tersimpan dalam makna batu pemberhentian. Sintesis apropriasi sejarah budaya Gunung Padang yaitu Gunung Padang menjadi suatu tempat sakral, suci, tempat menenangkan diri dari hal duniawi untuk mendapatkan petunjuk dari Yang Maha Kuasa. Gunung Padang juga sebagai bentuk penyadaran dan pengingat diri bahwa sejarah dan tradisi budaya perlu dijaga sebagai suatu penghormatan/ mengingat jasa para pendahulu.

2. Sejarah Desa Rawabogo

Desa Rawabogo sudah berdiri sejak abad ke-18. Nama Rawabogo berasal dari kata "Rawa" yang artinya situ/ sumber air dan "Bogo" yang merupakan nama ikan yaitu ikan bogo, dimana menurut sebagian warga desa menyebutkan bahwa terdapat ikan bogo yang khas berada di Mata Air Rawabogo. Sejarah terbentuknya Desa Rawabogo, saat itu terdapat pendatang dari wilayah Sukapura (Kabupaten Tasikmalaya) yang sudah memeluk agama Islam dan bermukim di daerah tersebut. Pada tahun 1874 sudah terdapat 38 rumah permukiman lalu pada tahun 1875 wilayah ini ditinjau oleh kolonial Hindia Belanda. Peninjauan tersebut karena ada hubungannya dengan tanam paksa (Cultuur stelsel) dimana terdapat tanda seperti pembukaan perkebunan teh dan pinus. Pada tahun 1877, Desa Rawabogo menjadi desa di bawah Karesidenan Soreang, Bandung Selatan.

Sintesis apropriasi sejarah Desa Rawabogo yaitu pembentukan nama Desa Rawabogo berhubungan dengan kondisi awal desa yang terdapat "rawa" berisi ikan "bogo" putih yang saat ini dikenal sebagai Mata Air Rawabogo. Desa terbentuk ketika hadir warga pendatang yang bermukim dan sudah membawa keyakinan agama Islam. Gunung Nagara Padang berkaitan dengan Desa Rawabogo karena hubungannya dengan beberapa kepala Desa Rawabogo yang juga sebagai juru kunci Gunung Nagara Padang. Hal yang tidak dapat dipisahkan dari desa ini yaitu adanya fenomena yang berkaitan dengan masa kemerdekaan Indonesia.

3. Ziarah Situs Gunung Nagara Padang

Situs Gunung Nagara Padang merupakan situs batu megalitik yang memiliki maknamakna dalam perjalanan kehidupan. Makna-makna tersebut dipengaruhi budaya Sunda dan agama Islam dari kebudayaan dan keyakinan masyarakat setempat. Pada situs tersebut terdapat 17 batu pemberhentian yaitu Batu Lawang Saketeng, Cikahuripan, Batu Kaca-Kaca, Batu Palawangan Ibu, Batu Bedak Paibuan, Batu Panyipuhan-Poponcoran, Batu Kaca Saadeg, Batu Gedong Peteng, Batu Karaton, Batu Kuta Rungu, Batu Masigit Agung, Batu Bumi Agung, Batu Korsi Gading, Batu Tugu Siliwangi, Batu Lawang Tujuh, Batu Padaringan Kebek-Leuit Salawe Jajar, dan Batu Puncak Manik. Batu-batu tersebut memiliki makna tersendiri yang secara umum mengenai perjalanan kehidupan manusia dari lahir hingga mencapai paripurna dan kembali 
kepada Yang Maha Kuasa. Sintesis apropriasi ziarah Situs Gunung Nagara Padang yaitu ziarah ini sebagai penelusuran spiritualitas dengan mengedepankan penghayatan kehidupan (masa kanak-kanak, masa kedewasaan, masa kematangan/ kebijaksanaan) dan menggali pengkajian diri melalui tradisi lisan kesundaan yang kini telah menjadi salah satu atraksi di Desa Rawabogo. Ziarah di situs ini sebagai bentuk pengingat untuk membangkitkan semangat hidup, menguatkan tekad dan meyakinkan langkah. Selain itu, setiap batu pemberhentian di Situs Gunung Nagara Padang menyampaikan makna dan nasihat terkait menjalani kehidupan serta hubungan diri, semesta dan Yang Maha Kuasa.

4. Tungku Tilu Jangka Opat Papat Kalima Pancer

Terdapat kutipan/ pepatah yang sering disebut oleh juru kunci Gunung Nagara Padang yaitu "Tungku tilu, jangka opat, papat kalima pancer", hal tersebut menjadi nilai turun temurun yang dipegang oleh pemangku adat di Desa Rawabogo. Tungku tilu memiliki arti bahwa terdapat tiga hal yang menjadi penopang kehidupan yaitu welas asih (adat), rohman rohim (agama), dan silihwangi (budaya). Jangka opat memiliki arti bahwa dalam kehidupan ini terdapat empat langkah atau 4 arah mata angin atau empat madzhab dalam Islam. Lalu papat kalima pancer memiliki arti bahwa dari empat arah atau empat madzhab tadi yang kelimanya merupakan pancer atau pusat yaitu Yang Maha Kuasa/ kanagaraan/ keyakinan diri masing-masing. Sintesis apropriasi nilai Tungku Tilu Jangka Opat Papat Kalima Pancer yaitu sebagai semboyan yang menjadi pedoman dasar untuk menjalani hidup. Nilai tersebut merupakan tradisi lisan yang dapat terus berkembang kaitan pemaknaannya. Nilai tersebut menjadi pengingat diri bahwa apabila ada permulaan maka ada akhir, apabila ada keragaman maka pelajari dahulu keragaman tersebut lalu pilih sesuai keyakinan hati.

5. Kegiatan Adat dan Kebudayaan

Kegiatan adat dan kebudayaan di Desa Rawabogo masih cukup kental terutama di Kampung Budaya Tutugan. Khas dari Desa Rawabogo ini hampir di setiap RW atau kampungnya memiliki potensi mempertahankan kesenian Sunda (seperti calung, tarawangsa, suling, kecapi, dll) dan pencak silat. Selain itu, terdapat kebudayaan Sisingaan yang dikelola oleh Padepokan Cisuren. Kampung Budaya Tutugan tepatnya di Padepokan Giri Padang/ Kasepuhan Ajar Padang yang dirasa lebih dominan dan kental terhadap kegiatan kebudayaan. Selain kesenian Sundanya, terdapat juga kegiatan Miasih Bumi Nagara Padang, Nyawang Bulan, Sangsaka Dwiwarna, dan Hajat Lembur. Sintesis apropriasi kegiatan adat dan kebudayaan yaitu kegiatan khas yang masih dipertahankan di Desa Rawabogo. Kegiatan yang telah menjadi salah satu daya tarik di Desa Rawabogo dan mendapatkan perhatian masyarakat luar desa. Kegiatan adat memiliki makna sebagai upaya menghormati para pendahulu dengan meneruskan dan mempertahankan kegiatan adat serta sebagai bentuk rasa syukur, berbagi dan mengharap keberkahan. Kegiatan kebudayaan juga sebagai upaya mempertahankan dan melestarikan kesenian Sunda di kalangan masyarakat terutama pemuda dan anak-anak.

6. Karakter Masyarakat

Karakter masyarakat merupakan ciri khas atau watak dari masyarakat Desa Rawabogo yang terbentuk dengan kesehariannya. Masyarakat Desa Rawabogo secara umum dirasa memiliki sifat kesundaan yang cukup melekat seperti bageur (baik), saling mengasihi dan berbagi, ramah, serta tidak sungkan untuk membantu memberi pertolongan. Namun, dari karakter positif tersebut membuat masyarakat Sunda termasuk masyarakat Desa Rawabogo juga memiliki sifat "tidak enakan" atau people pleaser. Sehingga terkadang sulit untuk mengungkapkan hal yang menjadi ganjalan dalam diri masing-masing atau kelompok, menghindari konflik dan cenderung mudah memaafkan/ menyudahi permasalahan. Sintesis apropriasi pada karakter masyarakat yaitu masyarakat Desa Rawabogo cenderung memiliki karakter kesundaan yang cukup kuat. Permasalahan di Desa Rawabogo dapat terjadi karena adanya kurang komunikasi dan tidak mau menghadapi konflik/ menyelesaikan permasalahan hingga benar selesai. Hal tersebut terjadi karena faktor karakter masyarakat yang "tidak enakan". Saat ini masyarakat Desa Rawabogo memiliki keinginan kuat untuk melestarikan budaya dan kebudayaan Sunda, namun kurang didukung rencana keberlanjutannya. 


\section{Pemaknaan Potensi Lokal Desa Wisata Rawabogo (Sintesis)}

1. Budaya sebagai Identitas Masyarakat Budaya dan Potensi Daya Tarik Desa Rawabogo. Budaya dan berbagai kegiatannya yang muncul di Desa Rawabogo menunjukkan keunggulan dan hal dominan yang terjadi di desa tersebut. Kegiatan budaya tersebut dikawal oleh masyarakat budaya yang berupaya mempertahankan warisan para pendahulu dan melestarikan budaya kebudayaan Sunda di kalangan generasi muda. Masyarakat budaya tidak tersebar di seluruh dusun Desa Rawabogo namun perannya cukup kuat untuk membangkitkan potensi budaya Sunda. Adanya potensi kuat dalam pelestarian budaya tersebut dapat menjadi peluang untuk dilestarikan lebih luas dengan menjadikannya potensi daya tarik Desa Rawabogo.

2. Gunung Nagara Padang sebagai Ciri Khas Desa Rawabogo. Gunung Nagara Padang sudah berkaitan dengan Desa Rawabogo sejak adanya juru kunci Situs Gunung Nagara Padang terdahulu yang juga sebagai kepala Desa Rawabogo. Gunung Nagara Padang berlokasi di perbatasan dengan Kabupaten Bandung Barat namun pengalaman kegiatan di situs tersebut sangat terasa di Desa Rawabogo yang dipelopori oleh masyarakat budaya. Hal tersebut menjadi ciri khas Desa Rawabogo karena keberadaan Situs Gunung Nagara Padang yang menjadi pembeda dari desa lainnya. Situs Gunung Nagara Padang pun menawarkan cerita dan nasihat perjalanan kehidupan melalui pemaknaan 17 batu pemberhentian. Pemaknaan tersebut yang menjadi unggulan keberadaan Gunung Nagara Padang di Desa Rawabogo.

3. Keberagaman Daya Tarik sebagai Peluang Desa Wisata Rawabogo. Selain daya tarik budaya dan Situs Gunung Nagara Padang, Desa Rawabogo memiliki potensi daya tarik lainnya yang berpeluang dikembangkan. Adanya Mata Air Rawabogo yang memiliki cerita terkait awal terbentuknya Desa Rawabogo, Mata Air Ciberecek yang menyuguhkan pemandangan alam, pertunjukkan adu domba, daya tarik wisata buatan seperti Puncak Kagagas dan Taman Desa Rawabogo merupakan suatu peluang besar untuk dapat menarik perhatian pengunjung apabila terus dikembangkan dengan baik. Suatu desa wisata akan lebih menarik banyak perhatian apabila menawarkan potensi yang beragam. Desa Rawabogo dengan segala potensi telah ada memiliki potensi signifikan untuk berkembang menjadi Desa Wisata Rawabogo. Hal tersebut tentu dengan memperhatikan potensi wisata yang melekat di Desa Rawabogo dan kolaborasi dalam pengembangannya.

Berdasarkan sintesis pemaknaan tersebut, hasil makna desa/ ruang dapat didialogkan dengan perencanaan dan berkaitan dengan perencanaan atau pengembangan desa wisata. Ruang akan menyampaikan dan memberikan suatu makna, sehingga makna ruang menjadi bagian integral dalam proses perencanaan ruang tersebut. Pengembangan desa wisata memiliki 4 tahapan/ posisi desa wisata sesuai kemajuan kondisinya yaitu rintisan, berkembang, maju dan mandiri. Desa Wisata Rawabogo dilihat dari kriteria karakter desa wisatanya termasuk ke dalam tahapan "berkembang". Berdasarkan permasalahan dan fenomena Desa Wisata Rawabogo maka desa tersebut perlu berbenah dan melakukan pengembangan. Fenomena di Desa Rawabogo dapat digali melalui pemaknaan desa atau melalui pendekatan fenomenologi-hermeneutik. Fenomenologi menjadi penting dalam konteks perencanaan sebagai suatu paradigma.

\section{Kesimpulan}

Berdasarkan pembahasan dalam penelitian ini, peneliti menyimpulkan beberapa hasil penelitian untuk menjawab pertanyaan permasalahan yaitu sebagai berikut:

1. Budaya sebagai identitas masyarakat budaya dan potensi daya tarik Desa Rawabogo. Budaya dan kebudayaan dominan muncul pada fenomena Desa Rawabogo dan berpotensi sebagai upaya pelestarian budaya Sunda serta menjadi daya tarik pengunjung untuk mengunjungi Desa Rawabogo.

2. Gunung Nagara Padang sebagai ciri khas Desa Rawabogo. Gunung Nagara Padang sebagai situs megalitikum dengan 17 batu pemberhentian yang memiliki pemaknaan tersendiri mengenai perjalanan kehidupan. Hal tersebut menjadi ciri khas dan sorotan masyarakat luar Desa Rawabogo karena keberadaan Situs Gunung Nagara Padang. 
3. Keberagaman Daya Tarik sebagai Peluang Desa Wisata Rawabogo. Selain budaya dan Gunung Nagara Padang, Desa Rawabogo memiliki potensi daya tarik wisata alam, buatan, dan edukasi yang berpeluang terus dikembangkan untuk mendukung pengembangan Desa Wisata Rawabogo.

4. Dialog pemaknaan potensi lokal Desa Rawabogo dengan perencanaan desa wisata yaitu pemaknaan potensi lokal dapat menjadi arah pengembangan daya tarik wisata budaya, keberlanjutan Gunung Nagara Padang dan pengembangan potensi wisata non-budaya. Permasalahan di Desa Wisata Rawabogo terjadi akibat pengembangan desa wisata yang belum memperhatikan dan mengembangkan potensi lokal.

\section{Acknowledge}

Alhamdulillahirabbil 'alamin, dengan terselesaikannya penelitian ini saya ingin mengucapkan terima kasih kepada seluruh pihak yang telah membantu dalam setiap tahapan penelitian ini. Saya ingin berterima kasih terutama kepada kedua orang tua saya dan keluarga, kepada dosen pembimbing saya Dr. Imam Indratno, S.T., M.T., kepada Prodi PWK UNISBA, kepada seluruh pihak di Desa Rawabogo, kepada rekan-rekan support system penulis, kepada rekan-rekan seperbimbingan Desa Rawabogo, serta kepada rekan-rekan PWK 2017 yang telah saling berbagi semangat dan mengisi kisah selama masa perkuliahan. Semuanya sangat berarti.

\section{Daftar Pustaka}

[1] Menteri Kebudayaan dan Pariwisata. 2010. Peraturan Menteri Kebudayaan dan Pariwisata tentang Pedoman Umun Program Nasional Pemberdayaan Masyarakat (PNPM) Mandiri Pariwisata Melalui Desa Wisata [Internet]. Jakarta: Menteri Kebudayaan dan Pariwisata. p. 1-21. Available from: http://www.kemenpar.go.id/userfiles/file/1_ PERMEN PNPM MANDIRI PARIWSATA DESA WISATA dan lampiran.pdf

[2] Sugiarto BAT, Siswantara Y. 2012. Rumah Budaya Sebagai Ruang Publik Untuk Mengembangkan Kegiatan Kepariwisataan Di Desa Wisata Rawabogo, Kecamatan Ciwidey, Kabupaten Bandung [Internet]. Available from: https://media.neliti.com/media/publications/12584-ID-rumah-budaya-sebagai-ruangpublik-untuk-mengembangkan-kegiatan-kepariwisataan-di.pdf

[3] El Mahdi L lzzah. 2007. Hermeneutika-Fenomenologi Paul Ricoeur: Dari Pembacaan Simboll Hingga Pembacaan Teks-Aksi-Sejarah. Hermeneia, J Kaji Islam Interdisip. 6(1):17-33.

[4] Hardiman FB. 2015. Seni Memahami Hermeneutik dari Schleiermacher sampai Derrida. Yogyakarta: PT Kanisius.

[5] A'inun N F, Krisnani H, Darwis RS. 2015. Pengembangan Desa Wisata Melalui Konsep Community Based Tourism. In: Prosiding Penelitian dan Pengabdian kepada Masyarakat [Internet]. $\quad$ p. 301-444. Available from: https://www.researchgate.net/publication/320325634\%0APENGEMBANGAN

[6] Faiz F. 2015. Ngaji Filsafat: Paul Ricoeur [Internet]. Yogyakarta: Masjid Jendral Sudirman. Available from: https://www.youtube.com/watch?v=L7uH_3CnK3A

[7] Agustina, I.H, Astri Mutia Ekasari, Irlan Fardhani, Hilwati Hindersah, 2020. Local wisdom in the spatial system of the palace, Indonesia. IOP Conference Series: Materials Science and $\quad$ Engineering. https://iopscience.iop.org/article/10.1088/1757899X/830/2/022077/meta

[8] Masruri S, Fauroni RL. 2013. Peran Modal Sosial Filsafat Tri Tangtu Silih Dalam Pemberdayaan Ekonomi Masyarakat Di Desa Alamendah Rancabali Bandung. Inferensi J Penelit Sos Keagamaan. 7(2):275-96.

[9] Djunatan S. 2008. Pola Rasionalitas dan Sistem Pengetahuan dalam Worldview Budaya Sunda Berdasarkan Situs Nagara Padang, Gunung Padang, Desa Rawabogo, Kecamatan Ciwidey, Kabupaten Bandung. Bandung: LPD Universitas Katolik Parahyangan.

[10] Aprilia ER, Sunarti, Pangestuti E. 2017. Pengaruh Daya Tarik Wisata Dan Fasilitas Layanan Terhadap Kepuasan Wisatawan di Pantai Balekambang Kabupaten Malang. J Adm Bisnis. 51(2):16-21. 
[11] Agustina, I.H dan Hilwati Hindersah, 2019. Explorations of Social Values in Magersari Settlement in Indonesia, ISVS e-journal, Vol. 6, no.1, https://isvshome.com/pdf/ISVS_61/ISVSej-6.1.1-InaHelenaAgustina.pdf

[12] Kementerian Pariwisata. 2019. Buku Pedoman Desa Wisata [Internet]. Jakarta: Deputi Bidang Pengembangan Industri dan Kelembagaan Kementerian Pariwisata. Available from: https://biroadpim.ntbprov.go.id/wp-content/uploads/2020/07/002-BUKUPANDUAN-DESA-WISATA-2020_compressed.pdf

[13] Indratno I. Madoang Dan Toma Rapu Sebagai Kesadaran Transendental Sistem Tondok (Permukiman) di Lembang Sillanan Kabupaten Tana Toraja. 2017; Available from: http://etd.repository.ugm.ac.id/ 